\title{
USE OF BACTERIA AND MICROALGAE IN SYNTHESIS OF NANOPARTICLES
}

\author{
Inga Zinicovscaia ${ }^{1,2}$ \\ ${ }^{1}$ Joint Institute for Nuclear Research, Joliot-Curie Str., 6, 1419890 Dubna, Russia \\ ${ }^{2}$ The Institute of Chemistry of the Academy of Sciences of Moldova, 3, Academiei Str., 2028 Chisinau, R. Moldova \\ E-mail: zinikovskaia@mail.ru
}

\begin{abstract}
A critical need in the field of nanotechnology is the development of a reliable and eco-friendly process for synthesis of metallic nanoparticles. A number of different organisms, including bacteria, microalgae, yeast and fungi, have shown their ability to produce metal nanoparticles. But they have some drawbacks in providing better control over size distribution, shape and crystallinity. This review article presents an overview of microorganisms (bacteria and microalga) capable of producing silver and gold nanoparticles. Also mechanisms of nanoparticles formation and parameters which influence their growth are discussed.
\end{abstract}

Keywords: nanotechnology, bacteria, microalga, nanoparticles, silver, gold.

\section{Introduction}

Nanotechnology is enabling technology with the ability to work at the atomic, molecular and submolecular levels in order to understand, create and use material structures, devices and systems with fundamentally new properties and functions resulting from their small structure [1-5].

The term nano is adapted from the Greek word meaning "dwarf." A nanometer (nm) is one billionth of a meter, or roughly the length of three atoms side by side. A DNA molecule is $2.5 \mathrm{~nm}$ wide, a protein approximately $50 \mathrm{~nm}$, and a flu virus about $100 \mathrm{~nm}$. A human hair is approximately 10,000 nm thick. A nanoparticle is a microscopic particle with at least one dimension less than $100 \mathrm{~nm}[6-8]$.

Scientists are developing reliable, eco-friendly techniques for atom-by-atom construction of objects that have potential applications in medicine, electronics, catalysis [9], photonics, optoelectronics [10], information technology, environmental monitoring and remediation, military equipment and weapons, and so forth [11-13]. An important area of research in nanotechnology deals with the synthesis of nanoparticles of different chemical compositions, sizes and controlled monodispersity [14].

The physical and chemical methods such as chemical reduction [15, 16], electrochemical reduction [17], photochemical reduction [18], are used for nanoparticle synthesis [19-21]. They have some significant disadvantages regarding formation, monodispersity of the particles and thermodynamic stability. In some processes special $\mathrm{pH}$ and temperature control is required to avoid aggregation and precipitation of the particles in solution. Such nanoparticles are stabilized by additional steps involving coating with polymer layers [22, 23]. Unfortunately many organic solvents are toxic enough to pollute the environment if large scale nanoparticles are produced.

This leads to a growing awareness of the need for developing clean, nontoxic and environmentally friendly procedures [24].

Many organisms, both unicellular and multicellular, are known to produce inorganic materials either intracellularly or extracellularly $[25,26]$. Microbial cells are highly organized units, regarding morphology and metabolic pathways, capable of synthesizing reproducible particles with well-defined size and structure. Advantages of biological methods include tightly controlled, highly reproducible syntheses: biocompatible particles: and the avoidance of toxic surfactants or organic solvents $[27,14]$. Furthermore, biogenic nanoparticles often exhibit water-soluble and biocompatible properties, which are essential for many applications [6].

One of the principle objectives in nanotechnology is the biosynthesis of noble metal nanoparticles.

The aim of present review is overview of various reports on biological synthesis of gold and silver nanoparticles using bacteria and microalgae.

\section{Using of microorganisms in nanoparticles synthesis}

\section{Bacteria in nanoparticle synthesis}

Among the microorganisms, prokaryotic bacteria have received the most attention in the area of biosynthesis of nanoparticles [28]. Moreover, bacteria are easy to handle and can be manipulated genetically. Considering these advantages, a bacterial system could prove to be an excellent alternative of chemical methods for the synthesis of gold nanoparticles [19].

Early studies reveal that Bacillus subtilis 168 is able to reduce $\mathrm{Au}^{3+}$ ions to produce octahedral gold particles

\footnotetext{
" This article is an extended abstract of a communication presented at the Conference Ecological Chemistry 2012.
} 
of nanoscale dimensions (5-25 nm) within bacterial cells by incubation of the cells with gold chloride under ambient temperature and pressure conditions [29].

Sastry and co-workers have observed that the extremophilic actinomycete, Thermomonospora sp. when exposed to gold ions reduced the metal ions extracellularly, yielding gold nanoparticles with a much improved polydispersity [14]. Ahmad with co-workers have showed that an alkalotolerant actinomycete, Rhodococcus sp., exposed to $\mathrm{AuCl}_{4}$ ions results in the rapid reduction of the gold ions and formation of fairly monodisperse intra-cellular nanoparticles. Furthermore, the concentration of gold nanoparticles is much higher on the cytoplasmic membrane than on the cell wall. It can be seen that the average particle size is $\approx 9 \mathrm{~nm}$ with some particles of 10-12 $\mathrm{nm}$ size and a very small percentage having diameters 5, 14 and $16 \mathrm{~nm}$.

Prokaryote bacteria Rhodopseudomonas capsulata, recognized as one of the ecologically and environmentally important microorganisms, commonly existing in the natural environment, was investigated for reducing $\mathrm{Au}^{3+}$ ions at room temperature with a single step process. It has been demonstrated that the bacteria Rhodopseudomonas capsulata are capable of producing gold nanoparticles extracellular and the gold nanoparticles are quite stable in solution [30].

Bacteria Desulfovibrio desulphuricans, Escherichia coli play an important role in fabrication of Au (0) particles of 20-25 nm size [31, 32].

Monodispersed spherical gold nanoparticles of $1.9 \pm 0.8 \mathrm{~nm}$ size have been synthesized extracellular by reaction of aqueous $\mathrm{AuCl}_{4}{ }^{-}$ions with Bacillus megatherium D01 [33].

Konishi et al. observed that Fe (III) reducing bacteria Shewanella algae can reduce Au (III) ions in anaerobic environments [34].

Pseudomonas stutzeri NCIMB 13420, Bacillus subtilis DSM 10, Pseudomonas putida DSM 291 tended to synthesize small, relatively uniform sized gold nanoparticles intracellular. The particles were observed mainly in the cytoplasm of the cells and the majority of the particles were spherical in shape [12].

The detailed study on extra-cellular biosynthesis of gold nanoparticles by the Pseodomonas aeruginosa was carried out in Husseiny work. Pseodomonas. aeruginosa is a Gram-negative bacterium that is capable of existing in multiple environmental niches and is an opportunistic pathogen, meaning that it exploits some break in the host defenses to initiate an infection [13].

Kalishwaralal et al. have reported a green chemistry approach using Bacillus licheniformis in the synthesis of gold nanocubes at room temperature without using any harmful reducing agents. The average particle size of nanocubes was found to be $10-100 \mathrm{~nm}[35]$.

The gold nanoparticles synthesized by Geobacillus stearothermophilu are essentially spherical and reasonably monodispersed. The mean particle size is $11 \mathrm{~nm}$. Some particles of 5-8 $\mathrm{nm}$ also could be visualized [36].

It is already established that silver is highly toxic to most microbial cells. Nonetheless, several bacterial strains are reported as silver resistant [37] and may even accumulate silver at the cell wall to as much as $25 \%$ of the dry weight biomass, thus suggesting their use for the industrial recovery of silver from ore material.

Klaus and co-workers have shown that the bacteria Pseudomonas stutzeri AG259 isolated from silver mine, when placed in a concentrated aqueous solution of $\mathrm{AgNO}_{3}$, resulted in the reduction of the $\mathrm{Ag}^{+}$ions and formation of silver nanoparticles of well-defined size and distinct morphology within the periplasmic space of the bacteria [28]. The size of such nanoparticles being in the range $16-40 \mathrm{~nm}$, with the average diameter of $27 \mathrm{~nm}$.

It was shown that silver nanoparticles can be synthesized by gram-negative bacteria Escherichia coli [38, 39] and Geobacter sulfurreducens [40].

Rapid synthesis of metallic nanoparticles of $\mathrm{Ag}$ using the reduction of aqueous $\mathrm{Ag}^{+}$ions has been achieved in the culture supernatants of Klebsiella pneumonia, Escherichia coli and Enterobacter cloacae [41]. Recently detailed studies confirmed that synthesis of Ag can be triggered through the liquid mixing process developed in the visible light spectrum by Klebsiella pneumonia [42].

The silver nanoparticles synthesized by Geobacillus stearothermophilu generally appeared spherical. The average size of nanoparticles is 5-35 $\mathrm{nm}$ [37].

Biosynthesis of silver nanaparticles by Lactobacilli acidophilus and Nannochloropsis oculata occurred at $10^{-3} \mathrm{M}$ of $\mathrm{AgNO}_{3}$ while the optimum concentration for producing silver nanoparticles for Lactobacilli casei, and Lactobacilli reuteri was $2 \cdot 10^{-3} \mathrm{M}$. The appropriate time for incubation of all species was 24 hours [24].

Nair and Pradeep have shown that Lactobacillus strains present in buttermilk, when challenged with silver and gold ions, resulted in the large-scale production of metal nanoparticles within the bacterial cells [43].

\section{Microalgae in nanoparticle synthesis}

Alga is a diverse group in plant kingdom that is not only accumulates metals by chelation and chemical transformation, but is also reported to produce bio-mineral structures and metal nanoparticles [44].

A few reports are available regarding gold accumulation using algal genera including cyanobacteria as bioreagent, such as Chlorella vulgaris, Spirulina platensis [45-48]. The morphological control over the shape of Au nanoparticles has been well established using Plectonema boryanum UTEX485, blue-green algae, while treated with aqueous Au $\left(\mathrm{S}_{2} \mathrm{O}_{3}\right)_{2}{ }^{3-}$ and $\mathrm{AuCl}_{4}$-solutions [47]. 
Kumar et al. have demonstrated the extracellular biosynthesis of silver, gold and bimetallic nanoparticles using Spirulina platensis. The use of blue green alga offers a means of developing 'nanofactories' for production of metal nanoparticles and it is clear that interaction of single-cell protein with inorganic materials can benefit much from effectively interfacing nanoparticles and biology [49].

Bioreduction of gold by Rhizoclonium riparium, Navicula minima and Nitzschia obtusa have already been reported by Nayak et al. and Pal et al. [22, 23]. In the Chakraborty's work, Lyngbya majuscula, Spirulina subsalsa and Rhizoclonium hieroglyphicum were exposed to radioactive and stable gold solution to study the absorption, recovery and nanogold formation [50].

Biosynthesis of silver nanoparticles by Chlorella vulgaris occurred at $10^{-3} \mathrm{M}$ of $\mathrm{AgNO}_{3}$ in 24 hours [24].

\section{Mechanism of nanoparticle synthesis}

The interactions between microorganisms and metals have been well documented and the ability of microorganisms to extract and/or accumulate metals is already employed in biotechnological processes such as bioleaching and bioremediation. But the cellular mechanism leading to the formation of nanoparticles is not well understood [51-55].

Ahmad et al. have postulated that microorganisms secrete enzymes, which may be responsible for the reduction of metal ions [56].

Nangia et al. suggested that the biosynthesis of gold nanoparticles and their stabilization via charge capping in Stenotrophomonas maltophilia involved NADPH-dependent reductase enzyme that converts $\mathrm{Au}^{3+}$ to $\mathrm{Au}^{0}$ through electron shuttle enzymatic metal reduction process [57].

Sastry and co-workers proposed that the silver ions are reduced by enzymes present in the cell wall leading to the formation of silver nuclei, which subsequently grow by further reduction of $\mathrm{Ag}^{+}$ions [14].

$\mathrm{Xie}$ et al. demonstrated that proteins are the principal biomolecules involved in the $\mathrm{Ag}^{+}$reduction and silver nanoparticles anisotropic growth in Chlorella vulgaris cells. Hydroxyl groups of amino acids are the most active functional groups for $\mathrm{Ag}^{+}$ions reduction [58].

Duran et al. also proposed the involvement of enzymatic electron shuttle relationship for the formation $\mathrm{of}^{\mathrm{Ag}^{+}}$ions and the subsequent formation of silver nanoparticle [59].

Binupriya et al. found that the assumed higher organic content leached out from inactive cells can be responsible for the higher and rapid productivity of gold and silver nanoparticles [60].

However, the biochemical mechanism of nanoparticles formation and stabilization remains unexplored.

\section{Size control over the biological synthesis of the nanoparticles}

Though, microbial synthesis is regarded as safe, cost-effective, sustainable and environment friendly processes, they have some drawbacks in providing better control over size distribution, shape and crystallinity. Optimizing the conditions such as $\mathrm{pH}$, temperature and incubation time, concentration of metal ions, and the amount of biological material have come up to give hope in implementation of these approaches in large scale and for commercial applications [61].

\section{Effect of $\mathrm{pH}$}

Gericke et al. have shown that the particles formed at $\mathrm{pH} 3$ were predominantly spherical in shape, relatively uniform in size, with the majority of the particles less than $10 \mathrm{~nm}$ in diameter. Nanoparticles synthesized at $\mathrm{pH} 5$ included small spherical particles; in addition a large number of bigger particles with well-defined shapes, including triangles, hexagons, spheres and rods also occurred at this $\mathrm{pH}$. The shapes of the particles formed at $\mathrm{pH} 7$ were similar to those formed at $\mathrm{pH} 9$ and included small spherical particles as well as bigger particles with irregular, undefined shapes [12].

Agnihotri and co-workers have observed for marine yeast Yarrowia lipolytica NCIM 3589 that acidic pH favored nucleation on the cell surfaces and the subsequent formation of gold crystals. At $\mathrm{pH} 7.0$ and 9.0, no crystals were formed. The average nanoparticle size was $15 \mathrm{~nm}$ [62]. A report by Gurunathan et al. showed that at acidic $\mathrm{pH}$ the size of the silver nanoparticle synthesized by Escherichia coli ranged $45 \mathrm{~nm}$ whereas at $\mathrm{pH} 10$ the size is just $15 \mathrm{~nm}$ [63].

Lengke et al. observed similar octahedral metallic gold using Plectonema boryanum UTEX 485 at pH 1.9-2.2 and $25-200{ }^{\circ} \mathrm{C}$ [47]. The nanoparticles synthesized by Rhodopseudomonas capsulata biomass at $\mathrm{pH}$ values 7 whereas a number of nanoplates were observed at $\mathrm{pH} 4$ [30].

\section{Effect of reaction temperature}

Huang et al. have shown that with temperature increase reaction rate of the conversion of the metal ion to nanoparticles grow up [64].

Gurunathanet al. showed that for Escherichia coli at room temperature, silver nanoparticles of $50 \mathrm{~nm}$ are synthesized whereas at $60{ }^{\circ} \mathrm{C}$ nanoparticles of $15 \mathrm{~nm}$ are synthesized [63].

Gerinke et al. used 3 temperatures for gold nanoparticles synthesis: 25,35 and $50^{\circ} \mathrm{C}$. At the lower temperatures, the majority of nanoparticles were spherical with an average diameter of less than $10 \mathrm{~nm}$. At $50^{\circ} \mathrm{C}$ very few small spherical particles were present. Formation of spherical particles was favored at low reduction rates, whereas high reduction rates resulted in the formation of particles exhibiting nanorod and platelet-like morphologies [12]. 
It is also observed that the low rate of reduction in metal ions at normal room temperature possibly facilitate the growth of anisotropic nanoparticles, and with slight modifications in the temperature and the reaction medium one can be enabled in fabricating the well-defined triangular gold nanoparticles [65].

\section{Effect of cell-free extract and metal salt concentration}

Pimprikar and co-workers analyzed effect of cell-free extract and metal salt concentration on the nanoparticle growth. $10^{11}$ cells $/ \mathrm{ml}$ yeast cell exposed to different concentration of $\mathrm{HAuCl}_{4}$ produce exclusive spherical nanoparticle. With $10^{10}$ cells $/ \mathrm{ml}$ in addition to the spherical nanoparticles hexagonal or triangular nanoplates of gold were also observed. With a lower number of cells $\left(10^{9} \mathrm{ml}^{-1}\right)$, the dose of the gold salt was reduced only when present in lower concentrations. This is connected with insufficient number of biomolecules which could reduce gold [66]. The same results were shown in $[67,68,12]$.

In Fig. 1 as example SEM micrographs of Spirulina platensis incubated with $\mathrm{HAuCl}_{4}$ of concentration $10^{-3}$ and $10^{-2} \mathrm{M}$ are presented.
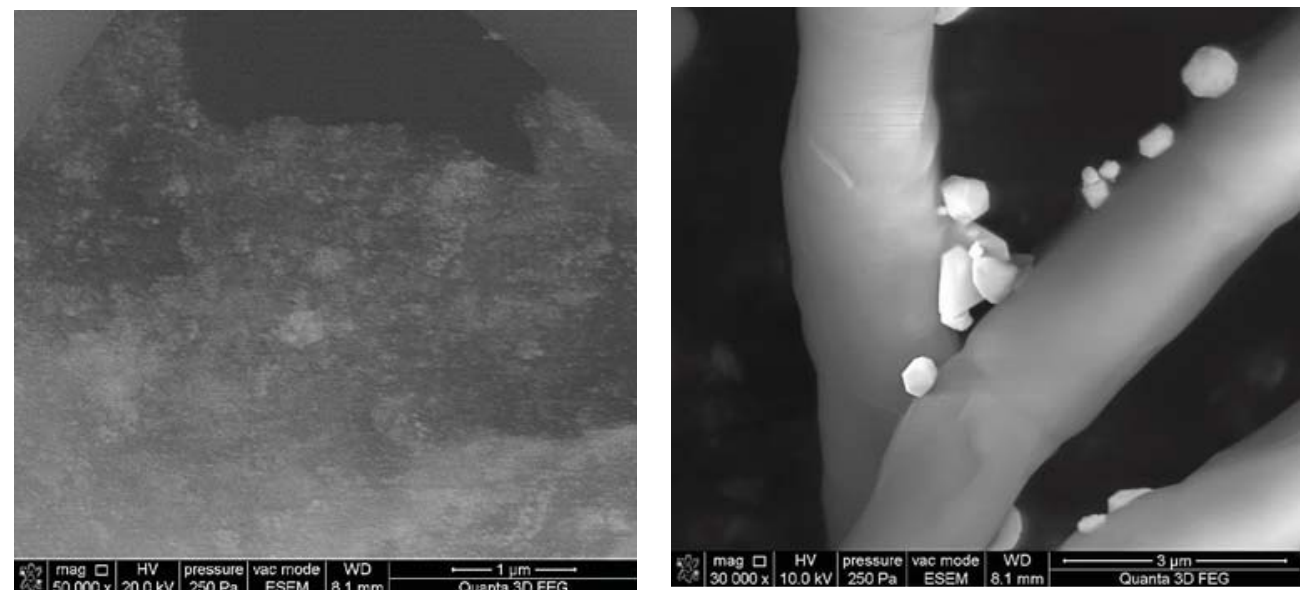

Fig. 1. SEM micrographs of Spirulina platensis cells exposed to $\mathrm{HAuCl}_{4}$ (a) concentration $10^{-3} \mathrm{M}$;

(b) concentration $10^{-2} \mathrm{M}$

\section{Effect of incubation time}

Incubation time also influence nanoparticles distribution. Usually after 24 hours of the metal ion action nanoparticles are well distributed along the microorganism's surface. Large agglomerates of nanoparticles could be observed after 5-6 days of reaction. The spherical nanoparticles produced in the beginning of the reaction were stable due to the protection by sufficient biomolecules but in contrast, the crystals that were formed later on might be less stable owing to fewer protective molecules [67]. Formation of metal nanoparticles of different shapes is kinetically driven process and is a result of aggregation and rearrangement of smaller size particles, which act as nuclei for further growth into anisotropic structures [68].

As example SEM images of Arthrobacter globiformis 151B taken after 40 hours and 3 days of reaction with $\mathrm{HAuCl}_{4}\left(10^{-3} \mathrm{M}\right)$ are presented in Fig.2.
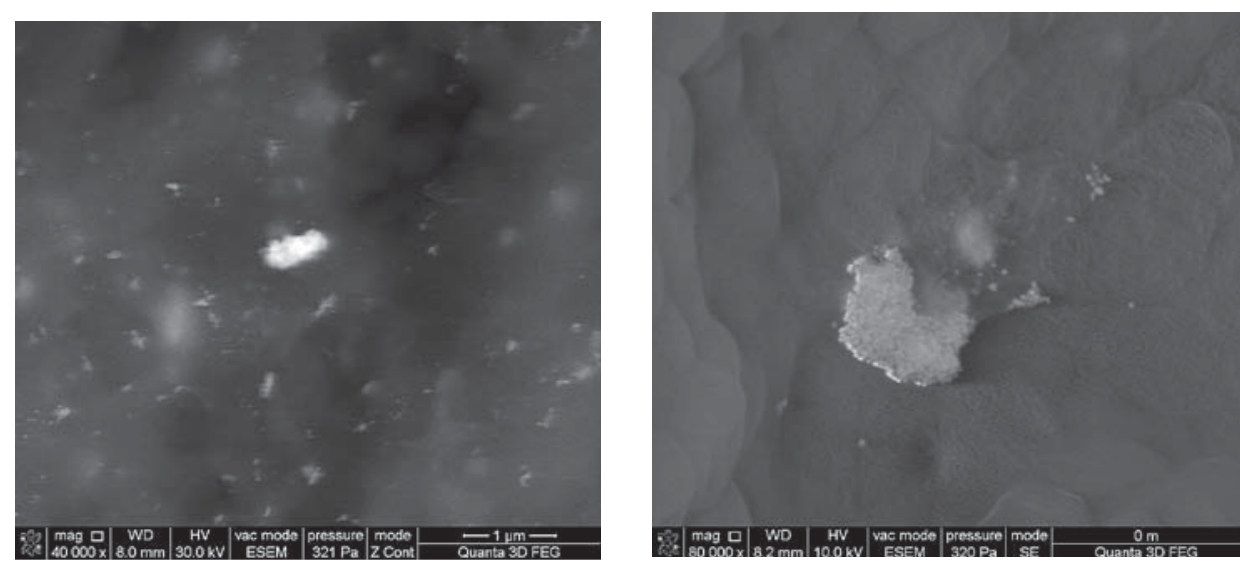

Fig. 2. SEM of A. globiformis cells (a) at $1 \mathrm{mM} \mathrm{HAuCl} 4$ for 40 hours; (b) at $1 \mathrm{mM} \mathrm{HAuCl} 4$ for 3 days 


\section{Application of nanoparticles}

In the past two decades, gold nanoparticles have significant role in nanotechnology due to their potential utilisation in nanoelectronics, semiconductors, colorimetric techniques, DNA labeling [69-71], in catalysis, chemical sensing, and photonics areas, owing to their unique chemical, optical, and physical properties [2].

Gold nanoparticles can traverse through the vasculature and localize any target organ. This potentially can lead to novel therapeutic, imaging, and biomedical applications [7].

It is well-know that the polymer-gold nanoparticles composites possess the interesting electrical properties [72]. The nanocomposites of Au and biopolymer are employed as a novel biosensor [73-75]. This biosensor exhibited a fast amperometric response and wide linear range of concentrations.

Gold nanoparticles can be applied to amplify the biorecognition of the anticancer drug [76].

The silver nanoparticles have several important applications in the field of biolabelling, sensors, drug delivery system, filters [20], antimicrobial industrial processes, catalysis, mirror production, electroplating, alkaline battery production, and jewelry production [40], spectrally selective coatings for solar energy absorption and intercalation material for electrical batteries, as optical receptors [77, 21].

Silver nanoparticles have important applications in the field of biology such as antibacterial agents and DNA sequencing.

Silver nanoparticles mainly in the range of $1-10 \mathrm{~nm}$ attach to the surface of cell membrane and drastically disturb its proper function like respiration and permeability [78].

The silver nanoparticles showed inhibition zone against E. coli ATCC 8739, Pseudomonas aeruginosa ATCC 9027, Staphylococcus aureus ATCC 6538P, Klebsiella pneumoniae (clinical isolate) [79].

Kim et al. reported antimicrobial activity of silver nanoparticles against E. coli and S. aureus [80].

\section{Conclusions}

The combination of biotechnology and nanotechnology created a new science nanobiotechnology. This new approach corresponds to the current scientific urge for improving the existing strategies for nanoparticle synthesis and inventing new ones. Although the ability of living cells to build up spatial structures is hardly employed in applications, there is evidence ensuring that the potential of microorganisms to produce inorganic nanoparticles will be fully exploited in technically relevant dimensions in the near future. Thus, nanotechnology promises to play an increasingly important role in many key ecological friendly technologies of the new millennium.

\section{References}

[1] Nanotechnology and the Environment: Applications and Implications Progress Review Workshop III October 26-28, 2005 Arlington, VA.

[2] Thirumurugan, G.; Shaheedha, S. M.; Dhanaraju, M. D. Int. J. Chem. Tech Res. 2009, 1(3), 714-716.

[3] Sau, T. K.; Pal, A.; Jana, N. R.; Wang, Z. L.; Pal, T. J. Nanopart. Res. 2001, 3, 257-261.

[4] Roco, M. C. Curr. Opin. Biotechnol. 2003, 14, 337-346.

[5] Bowman, D. M.; Hodge, G. A. Futures. 2006, 38(9), 1060-1073.

[6] Krumov, N.; Perner-Nochta, I.; Oder, S.; Gotcheva, V.; Angelov, A.; Posten C. Chem. Eng. Technol. 2009, 32(7), $1026-1035$.

[7] Kaushik, N.; Thakkar, M. S.; Snehit, S.; Mhatre, M.S.; Rasesh, Y.; Parikh, M.S. Biol.Sci. 2010, 6(2), 257-262.

[8] Salib, M.; Nanotechnology. Bibliotheca Alexandrina, 1-17.

[9] Mourato, A.; Gadanho, M.; Lino, A. R.; Tenreiro, R. Bioinorg. Chem. Appl. V. 2011, 1-8.

[10] Begum, N. A.; Mondal, S.; Basu, S.; Laskar, R. A.; Mandal, D. Colloids Surf. B: Biointerfaces. 2009, 71, 113118.

[11] Mehta, D. M. Bull. Sci. Technol. Soc. 2004, 24 (1), 34-39.

[12] Gericke, M.; Pinches, A. Hydrometallurgy. 2006, 83, 132-140.

[13] Husseiny, M.I.; Abd El-Aziz, M.; Badr, Y.; Mahmoud, M.A. Spectrochim. Acta Part A. 2007, 67, 1003-1006.

[14] Sastry, M.; Ahmad, A.; Islam Khan, M.; Kumar, R. Curr. Sci. 2003, 85(2), 162-170.

[15] Yu, D. G. Colloids Surf. B. 2007, 59, 171-178.

[16] Petit, C.; Lixon, P.; Pileni, M. P. J. Phys. Chem. 1993, 97, 12974-12983.

[17] Liu, Y.C.; Lin, L.H. Electrochem. Commun. 2004, 6, 1163-1168.

[18] Mallick, K.; Witcombb, M. J.; Scurrella, M. S. Mater. Chem. Phys. 2005, 90, 221-224.

[19] Nithya, R.; Ragunathan, R. Digest J. Nanomat. Biostruct.2009, 4 (4), 623 - 629.

[20] Ingle, A.; Rai, M.; Gade, Bawaskar, A. M. J. Nanopart. Res. 2009, 11, 2079-2085.

[21] Hutchinson, T. O.; Yun-Ping L.; Kiely, C.; Kiely, C. J.; Brust, M. Adv. Mater. 2001, 13 (23), 1800- 1803.

[22] Nayak, D.; Nag, M.; Banerjee, S.; Pal, R.; Laskar, S.; Lahiri. S. J. Radioanal. Nucl. Chem., 2006, 268, $337-$ 340 . 
[23] Chakraborty, N.; Pal, R.; Ramaswami, A.; Nayak, D.; Lahiri. S. J. Radioanal. Nucl. Chem. 2006, 270, 645-649.

[24] Mohseniazar, M.; Barin, M.; Zarredar, H.; Alizadeh, S.; Shanehbandi, D. BioImpacts. 2011, 1(3), $149-152$.

[25] Bhattacharya, D.; Gupta, R. K. Crit. Rev. Biotechnol. 2005, 25, 199-204.

[26] Mohanpuria, P.; Rana, N. K.; Kumar Yadav, S. J Nanopart Res. 2008, 10, 507-517.

[27] Narayanan, K. B.; Sakthivel, N. Colloids Surf. A: Physicochem. Eng. Aspects. 2011, 380, 156-161.

[28] Klaus-Joerger, T.; Joerger, R.; Olsson, E.; Granqvist, C. G. Trends Biotechnol. 2001, 19, 15-20.

[29] Beveridge, T.J.; Murray, R.G.E. J. Bacteriol. 1980, 141, 876-887.

[30] He, S.; Guo, Z.; Zhang, Y.; Zhang, S.; Wang, J.; Gu, N. Mater. Lett. 2007, 61, 3984-3987.

[31] Deplanche, K.; Macaskie, L. E. Biotechnol. Bioeng. 2008, 99 (5), 1055-1064.

[32] Sinha, S.; Pan, I.; Chanda, P.; Sen, S. K. J. Appl. Bioscie. 2009, 19, 1113 - 1130.

[33] Wen, L.; Lin, Z.; Gu, P.; Zhou, J.; Yao, B.; Chen, G.; Fu, J. J. Nanopart. Res. 2009, 11, 279-288.

[34] Konishi, Y.; Tsukiyama, T.; Tachimi, T.; Saitoh, N.; Nomura, T.; Nagamine, S. Electrochim. Acta, 2007,53 (1), 186-192.

[35] Kalishwaralal, K.; Deepak, V.; Pandian, S. R. K.; Gurunathan, S. Bioresour. Technol. 2009, 100, 5356-5358.

[36] Fayaz, A. M.; Girilal, M.; Rahman, M.; Venkatesan, R.; Kalaichelvan, P.T. Process Biochem. 2011, 46, $1958-1962$.

[37] Silver, S. FEMS Microbiol .Rev. 2003, 27, 341-353.

[38] Pal, S.; Tak, Y. K.; Song, J. M. Appl. Environ. Microbiol. 2007, 73(6), 1712-1720.

[39] Gurunathan, S.; Kalishwaralal, K.; Vaidyanathan, R.; Venkataraman, D.; Pandian, S. R. K.; Muniyandi, J.; Hariharan, N.; Eom, S. H. Colloids Surf B Biointerfaces. 2009, 74(1), 328-335.

[40] Law, N.; Ansari, S.; Livens, F. R.; Renshaw, J. C.; Lloyd, J. R. Appl. Environ. Microbiol. 2008, 74(22), $7090-7093$.

[41] Shahverdi, A. R.; Minaeian, S.; Shahverdi, H. R.; Jamalifar, H.; Nohi, A.A. Process Biochem. 2007, 42, $919-923$.

[42] Mokhtari, N.; Daneshpajouh, S.; Seyedbagheri, S; Atashdehghan, R.; Abdi, K.; Sarkar, S.; Minaian, S.; Shahverdi, H. R..; Shahverdi, A. R. Mater. Res. Bull. 44, 1415-1421.

[43] Nair, B.; Pradeep, T. Cryst Growth Des, 2002, 2, 293-298.

[44] Singh, A.; Mehta, S. K.; Gaur, J. P. World J. Microbiol. Biotechnol. 2007, 23, 1115-1120.

[45] Ting, Y. P.; Lawson, F.; Prince, I. G. J. Appl. Phycol. 1995, 7, 97-100.

[46] Savvaidis, I.; Karamushka, V. I.; Lee, H.; Trevors. J. T. BioMetals. 1998, 11, 69-78.

[47] Lengke, M.F.; Ravel, B.; Fleet, M. E.; Wanger, G.; Gordon, R.A.; Southam. G. Environ. Sci. Technol. 2006, 40(20), 6304-6309.

[48] Lengke, M.F.; Fleet, M.E.; Southam, G. Langmuir, 2006, 22, 2780-2787.

[49] Kumar, V. G.; Singaravelu. G. J. Mater. Sci. 2008, 43, 5115-5122.

[50] Chakraborty, N.; Banerjee, A.; Lahiri, S.; Panda, A.; Ghosh, A. N.; Pal. R. J. Appl. Phycol. 2009, 21, $145-152$.

[51] Vijayaraghavan, K.; Yun, Y. S. Biotechnol. Adv. 2008, 26, 266-291.

[52] Gadd, G. M.; Griffiths, A. J. Microbial Ecol. 1978, 4, 303-317.

[53] Dhankhar, R.; Guriyan, R. B. Intern. J. Adv. Sci. Technol. 2011, 2 (6), 1-6.

[54] Farooq, U.; Kozinski, J. A.; Khan, M. A.; Athar, M. Bioresour. Technol. 2010, 101, 5043-5053.

[55] Haferburg, G.; Kothe, E. J. Basic Microbiol. 2007, 47, 453-467.

[56] Ahmad, A.; Mukherjee, P.; Senapati S.; Mandal, D.; Khan, M.I.; Kumar, R.; Sastry, M. Colloids Surf. B Biointerfaces 2003, 28, 313-318.

[57] Nangia,Y.; Wangoo, N.; Goya, N.; Shekhawat, G.; Suri, C. R. Microbial Cell Factories 2009, 8(39), 1-7.

[58] Xie, J.; Lee, J.Y.; Wang D.I.C.; Ting, Y.P. ACS Nano. 2007, 1, 429-439.

[59] Duran, N.; Marcato, P.D.; Alves, O.L.; Souza, G.; Esposito, E. J Nanotechnology. 2005, 3, 8-14.

[60] Binupriya, R.; Sathishkumar, M.; Yun, S. I. Colloids Surf. B, 2010, 79(2), 531-534.

[61] Narayanan, K. B.; Sakthivel, N. Colloids Surf. A: Physicochem. Eng. Aspects. 2011, 380, $156-161$.

[62] Agnihotri, M.; Joshi, S.; Kumar, A. R.; Zinjarde, S.; Kulkarni, S. Mater. Lett. 2009, 63, 1231-1234.

[63] Gurunathan, S.; Lee, K. J.; Kalishwaralal, K.; Sheikpranbabu, S.; Vaidyanathan, R.; Eom, S. H. Biomaterials, 2009, 30, 6341-6350.

[64] Huang, J.; Lin, L.; Li, Q.; Sun, D.; Wang, Y.; Lu, Y.; He, N.; Yang, K.; Yang, X.; Wang, H.; Wang, W.; Lin, W. Ind. Eng. Chem. Res. 2008, 47, 6081-6090.

[65] Shankar, S. S.; Rai, A.; Ahmad, A.; Sastry, M. Chem. Mat. 2005, 17, 566-572.

[66] Pimprikar, S.; Joshi, S.S.; Kumar, A.R.; Zinjarde, S.S.; Kulkarni, S.K. Colloids Surf. B: Biointerfaces. 2009, 74, 309-316.

[67] Narayanan, K. B.; Sakthivel, N. Colloids Surf. A: Physicochem. Eng. Aspects. 2011, 380, $156-161$.

[68] Verma, S. V.; Singh, C. K.; Solanki, R.; Prakash, S. Nanoscale Res. Lett. 2011, 6, 16, 1-7.

[69] McConnell, W. P.; Novak, J. P.; Brousseau, L. C.; Fuierer, R. R.; Tenent, R. C.; Feldheim, D. J. Phys. Chem. B, 2000, 104 (38), 8925-8930.

[70] Dawson, A.; Kamat, P. V. J. Phys. Chem. B. 2001, 105 (5), 960-966.

[71] Yungjin, K.; Johnson, R.C.; Hupp, J.T. Nano Lett, 2001, 1, 165-167. 
[72] Guo, S.; Wang, E. Analytica Chimica Acta, 2007, 598, 181-192.

[73] Sperling, A.R.; Gil, R. P.; Zhang, F.; Zanella, M.; Parak, J.W. Chem. Soc. Rev. 2008, 37, 1896-1908.

[74] Shakibaie, M.; Forootanfar, H.; Mollazadeh-Moghaddam, K.; Bagherzadeh, Z.; Nafissi-Varcheh, N.; Reza Shahverdi, A.; Faramarzi, M. A. Biotechnol. Appl. Biochem. 2010, 57, 71-75.

[75] Zhu, S.; Du, C.L.; Fu, Y. Optical Materials, 2009, 31, 769-774.

[76] Shen, Q.; Wang, X.; Fu, D. Applied Surface Sci. 2008, 255, 577-580.

[77] Kasture, M B.; Patel, P.; Prabhune, A. A.; Ramana, C. V.; Kulkarni, A. A.; Prasad, B. J. Chem. Sci. 2008,120 (6), 515-520.

[78] Morones, J. R.; Elechiguerra, L. J.; Camacho, A.; Holt, K.; Kouri, B. J.; Ramirez, T. J.; Yocaman, J. M. Nanotechnology, 2005, 16, 2346-2353.

[79] Raut, R. W.; Lakkakula, J. R.; Kolekar, N. S.; Mendhulkar V. D.; Kashid S. B. Current Nanoscience, 2009, 5, 117-122.

[80] Kim, J. S.; Kuk, E.; Yu, K. N.; Kim, J. H.; Park, S. J.; Lee, H. J.; Kim, S. H.; Park, Y. K.; Park, Y. H.; Hwang, C. Y.; Kim, Y. K.; Lee, Y. S.; Jeong, D. H.; Cho, M. H. Nanomedicine: Nanotechnol. Biol. Med., 2007, 3, 95-101. 